\title{
A multiplicidade das dinâmicas sob o cotidiano sonoro
}

\author{
Alexandre Provin Sbabo
}

\author{
PEREIRA DE SÁ, S.; POLIVANOV, \\ B.; EVANGELISTA, S. (org.) \\ Música, som e cultura digital: \\ Perspectivas comunicacionais \\ brasileiras. 1. ed. - Rio de Janeiro: \\ E-papers, 228 p., 2016.
}

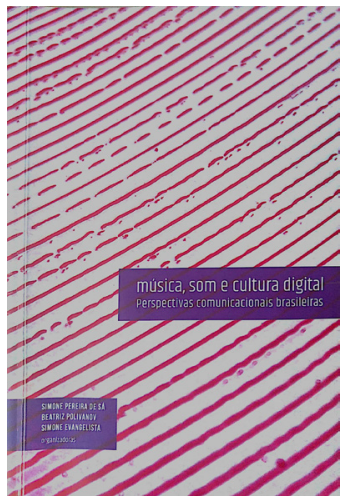

Resumo: O livro organizado por Simone Pereira de Sá, Beatriz Polivanov e Simone Evangelista apresenta uma reunião de textos que celebra os dez anos de existência do Laboratório de Pesquisa em Culturas e Tecnologias da Comunicação da Universidade Federal Fluminense (LabCult/UFF) e compartilha com seus leitores a pluralidade de objetos e saberes que circunscrevem o grupo, atentando sempre para o viés comunicacional do campo musical e sonoro em interação com as dinâmicas sociais.

Palavras-chave: cena musical; dinâmicas sociais; música; som; territorialidades.

Abstract: The multiplicity of dynamics beneath the daily sound - The book organized by Simone Pereira de Sá, Beatriz Polivanov and Simone Evangelista presents a reunion of texts that celebrates the ten years of existence of the Research Laboratory of Cultures and Communication Technologies from Fluminense Federal University (LabCult / UFF) and shares with its readers the plurality of objects and knowledge that circumscribe the group, always attentive to the communication bias of the musical and sound fields in interaction with social dynamics.

Keywords: musical scene; social dynamics; music; sound; territorialities. 
O livro Música, som e cultura digital: perspectivas comunicacionais brasileiras, organizado pelas professoras Simone Pereira de Sá, Beatriz Polivanov e Simone Evangelista Cunha, é uma obra que comemora os dez anos de existência do Laboratório de Pesquisa em Culturas e Tecnologias da Comunicação da Universidade Federal Fluminense (LabCult/ UFF). Cabe, portanto, iniciarmos nossa resenha ressaltando o papel fundamental da apresentação, pois, para nós, ler um livro sem considerar sua apresentação é renegar o caráter humano, criativo, intelectual e laborioso da escrita e da pesquisa.

$\mathrm{Na}$ apresentação, as organizadoras do livro apresentam, sobretudo, os interesses e a forma de trabalho do grupo, mostrando uma ampla área de atuação que vai desde temas relacionados à terminologia musical e à crítica musical, passando pelo caráter estético, político, territorial, midiático, antropológico e matérico do consumo e da escuta da música. Além disso, somos apresentados à metodologia de trabalho do LabCult e suas respectivas referências teóricas, com destaque para a consideração da perspectiva imanente de cada um dos objetos analisados.

Partindo para a primeira parte do livro, denominada Mediações e $(m)$ cenas e gêneros musicais, encontramos aqui um conjunto de sete textos que exploram as relações dos temas apresentados anteriormente, com as especificidades de determinados gêneros e/ ou cenas musicais.

O primeiro texto, intitulado Sertanejo, manguebeat e tchê music: Da pertinência (ou não) do conceito de cena musical para gêneros periféricos de Amílcar Bezerra, Gustavo Alonso e Henrique Reichelt, apresenta uma breve contextualização do mercado fonográfico e sua transformação em decorrência da utilização das mídias digitais, tanto no que diz respeito à gravação, como sua distribuição e consumo, o que por sua vez incentivou a territorialização de cenas musicais. Desta forma, os autores buscam avaliar a "aplicabilidade" do conceito de cena musical a partir dos gêneros citados no título do texto.

Assim sendo, somos introduzidos às características que compõem a construção da chamada cena musical, as quais acabam, por fim, desvelando as relações e construções midiáticas entre gêneros e cenas musicais que nem sempre se apresentam de forma simples e clara, demonstrando os problemas do uso indiscriminado e a complexidade de tal conceito. Um texto fácil de ler e que nos faz questionar o quanto cercear manifestações estéticas dentro de um determinado rótulo, sendo este cena ou gênero, é relevante para uma construção identitária, assim como para a existência de uma potência criativa e reflexiva no contexto musical e cultural.

O segundo texto da primeira parte, intitulado Rock RJ: Articulações entre cenas musicais e dinâmicas de coletivos culturais do Estado do Rio de Janeiro, dos autores Simone Pereira de Sá, Luiza Bittencourt e Daniel Domingues, traz uma discussão sobre as relações entre a cena musical do gênero do rock e nove coletivos culturais no estado do Rio de Janeiro.

Após apresentar a delimitação do corpus e a metodologia da pesquisa de forma clara e objetiva, os autores mostram a construção das narrativas dos coletivos selecionados, 
destacando o perfil da gestão cultural e como estes contribuem para a manutenção e fomento da cena musical na qual estão inseridos, tanto singularmente, como em relação com outros coletivos e com sua rede de contatos. A partir deste ponto, extraímos uma série de informações relevantes para refletir, não somente sobre a gestão cultural destes coletivos, mas também sobre como suas ações contribuem para a construção de uma identidade e para a dinâmica entre consumo, circulação e produção da cena musical.

O terceiro texto desta mesma parte, $A$ indústria cultural e suas instâncias de consagração: $O$ caso da música eletrônica de Marcelo Garson, apresenta de maneira interessante a construção de diferentes narrativas de instâncias de consagração. De um lado a consagração estética; do outro a consagração da indústria cultural que, nefastamente, subverte a estética de maneira que se adeque às instâncias mercadológicas.

Partindo deste ponto de vista e da polêmica consagração do D/ Tiesto pela indústria cultural como o "melhor $D J$ do mundo", o autor procura analisar o fórum de discussão de um dos maiores websites, até então, sobre música eletrônica, o rraurl.com", entre os anos de 2003 e 2009, para nos mostrar como os "seguidores" da cena underground e da cena mainstream buscam legitimar seus discursos.

Devemos ressaltar que a discussão sobre universos simbólicos e discursos de legitimação dos dois lados da cena nos mostra como a consagração de um determinado artista, por meio da indústria cultural, incomoda os chamados "iniciados" ou os "cultos" da fruição da escuta, pois de fato evoca outro universo simbólico. Contudo, somos lembrados que a consagração da indústria cultural também é responsável por popularizar um movimento ou uma cena e que, desta maneira, o cenário musical se mantém vivo e atualizado. Ainda assim, o autor poderia ter deixado mais evidente que a discussão em si, conforme as próprias postagens selecionadas, está mais voltada para a legitimação de uma cena musical outrora incluída no underground (o trance), mas aparentemente subvertida pela indústria cultural, motivando assim, os participantes do site à construção de discursos de legitimação do gosto, seja este do underground ou não.

Continuando na primeira parte do livro, o quarto texto, intitulado Fabricando ou produzindo Popstars? Disputas do circuito musical a partir de um reality show de Heitor Luz, procura explorar, por meio da mediação da televisão, o processo de construção de um novo grupo musical a partir das interações, relações e de um conjunto de valores intercambiados entre o produto da mídia televisiva e a indústria musical.

Desta forma, o autor nos apresenta todo o processo de seleção e de "formação", ou "construção", de artistas do reality show Popstars do ano de 2002, suas narrativas e tentativas de legitimação de um discurso em prol da "essência" de cada participante por meio de um processo aparentemente transparente.

1 O website http://www.rraurl.com teve suas atividades encerradas em 2016 e com isso sua base de dados não existe mais. 
Contudo, também somos apresentados ao discurso crítico de tal "fabricação" de artistas, o que eleva substancialmente as considerações apontadas pelo autor, principalmente no que diz respeito aos valores permanentemente buscados pelo programa e pela indústria da música que, ao mesmo tempo no qual fabricam o artista, com testes, seleções, lições, aulas etc., estão fabricando seu público por meio do reality show. Um texto que nos convida a refletir sobre tais processos manipulatórios que subvertem a arte em prol de leis mercadológicas, argumento, este sim, legitimado pela breve existência de tais artistas fabricados.

O quinto texto da primeira parte, Performatividade de gênero na música popular periférica de Luciana Xavier, Simone Evangelista e Thiago Soares, procura debater as relações estéticas, políticas, de gênero e hierárquicas dos discursos de poder hegemônicos e subalternos presentes nos modos de ser, de estar, de parecer e de fazer de duas artistas transexuais, a saber, MC Xuxú e Titica, por meio de seus respectivos videoclipes: "Quero ficar" e "Olha o boneco". Além disso, os autores questionam a presença do universo pop e das divas pop, também no corpo das artistas, evocando assim as relações de formas simbólicas dos sujeitos e a dimensão política de tais questões.

Os autores conseguiram trabalhar com um assunto delicado e polêmico de maneira clara, objetiva e bastante técnica. Um olhar realmente interessante sobre como os discursos, as práticas, a enunciação e os modos de existência auxiliam na construção identitária e no rompimento de paradigmas. Contudo, por tratar de um tema que exige sensibilidade social e acreditando que o fazer do pesquisador deve extrapolar o campo científico e dialogar com a sociedade, assim como com suas práticas, seria válido mencionar o trabalho que a Associação Nacional de Travestis e Transexuais (ANTRA) realiza, uma vez que possui total relação com os "jogos simbólicos" analisados, auxiliando na construção de conceitos, colaborando na obliteração de conflitos e tomando o cuidado para não cair em estereótipos midiatizados pela indústria musical e cultural.

Sem dúvida, as relações das formas simbólicas permeando diversos conjuntos de valores e esferas da significação com vistas a desmistificação do preconceito e da polaridade qualificadora, tornam este trabalho referência em diversas áreas, não só do campo acadêmico, mas do campo social como um todo.

No penúltimo texto da primeira parte do livro, Percursos do pop português contemporâneo na Last.fm: Novas dinâmicas de recomendação musical e classificação por gênero, Tiago Monteiro explora as relações e articulações que o website Last.fm realiza ao construir uma cartografia pop para recomendar aos seus usuários em contrapartida com o discurso hegemônico de uma crítica musical buscando sustentar sua legitimidade enquanto instituição. Isto leva o autor a investigar a curiosa divergência de dados sobre o consumo musical onde, de um lado, temos a Associação Fonográfica Portuguesa e, de outro, a imprensa e a crítica musical que buscam legitimar seu discurso.

É interessante notar que este conflito de discursos aparece quando um novo actante, com competência para construir uma cartografia musical por meio de dados 
informatizados, se apresenta em um ambiente no qual, até então, somente uma crítica do "bom gosto" poderia operar e emitir juízos de valores e classificatórios. Porém, como o próprio autor justifica em suas considerações finais, provavelmente pelo pouco tempo disponível, apresentou-se um trabalho bastante incipiente e que apenas nos mostrou o caráter poroso, mas ainda limitado, da cartografia musical do software do Last.fm para o gênero musical pop português.

O sétimo e último texto da primeira parte, Construindo identidades na música gospel: Reflexões sobre pesquisa etnográfica nos sites de redes sociais de Olívia Bandeira, explora, a partir da antropologia digital, como as identidades de artistas gospel são articuladas e manifestam modos de ser e estar no ambiente virtual, contribuindo assim para a construção de um espaço de pesquisa etnográfico nas redes sociais.

A apresentação da metodologia, das justificativas e de todas as escolhas que envolvem o fazer científico são, de fato, muito bem apontadas pela autora, tornando o texto claro e fácil de ser compreendido, mesmo para aquele leitor que não possui contato com o tema ou com a bibliografia utilizada. Torna-se relevante ressaltar que a pesquisa, talvez pelo seu caráter etnográfico multissituado, tenha deixado algumas questões um pouco de lado, como por exemplo, ao falar de identidade só há uma breve passagem pela noção de alteridade e pelo que pode ser conhecido como regimes de visibilidade. Neste ponto acredito que as contribuições de Landowski (1992, 2002), no que diz respeito aos regimes de visibilidade e aos conceitos de identidade e alteridade, poderiam ampliar de forma significativa e criticamente o debate pretendido sobre as redes sociais como ferramenta de pesquisa antropológica.

A segunda parte do livro, denominada Materialidades, sonoridades e afetações, composta por seis textos, aborda, em linhas gerais, as dinâmicas e relações que as materialidades estabelecem com o consumo e a fruição da música, tema bastante atual e necessário, uma vez que atualmente encontramos a música em diferentes formatos matéricos, tendo cada qual a sua representatividade simbólica.

O primeiro texto da segunda parte, Topografias eletrônicas: Por uma noção de materialidade em mídias digitais de José Cláudio Castanheira, Beatriz Polivanov e Alessandra Maia, inaugura a discussão sobre a materialidade dos objetos refletindo sobre como as relações humanas são mediadas não somente pelos softwares em si, mas também pela materialidade inerente a tais práticas. Desta forma, afirmar que as condições ou as características materiais não atualizam as dinâmicas e as interações torna-se algo impensável, uma vez que é a partir e por meio do matérico que outras interações e afetos se presentificam.

Para isso, os autores elencam os modos de se relacionar com os objetos e acreditam que estes modos criam uma dinâmica que concede pistas das materialidades presentes no meio digital de tal forma que, a maneira como nos relacionamos com as coisas, nos fornecem subsídios para compreendermos as materialidades dos objetos analisados.

A ideia de que o software pressupõe, de saída, a existência do hardware é interessante, 
pois rompe com a dicotomia entre o imaterial/material e nos convida a apreendermos nossas relações com o meio digital de outra maneira. Realmente, trata-se de um tema ainda muito pouco explorado, mas que, além das contribuições citadas no texto, acrescentaria a pesquisa de Costa (2016) que não somente trabalha com a questão da materialidade da revista Elle Brasil analogicamente, como também com o espaço digital da revista e inclusive com as interações propostas entre as diferentes materialidades. Pensar no digital, também é pensar no matérico que nos leva até esse universo, pois é essa materialidade que, de uma forma ou outra, nos prescreve certas práticas.

O rompimento da dicotomia imaterial/material abre espaço para considerarmos tais relações de maneira sincrética e indissociáveis, eleitas não por oposições, mas por pressuposições, ampliando a noção de analógico e digital e nos convidando a repensarmos nossas interações com o ambiente virtual.

O segundo texto desta mesma parte, Jogos locativos, espaço urbano e música: Rumo a um ambiente (lúdico) sensorial ressonante de Luiz Adolfo Andrade e Macello Medeiros, ressalta as dinâmicas entre os jogos locativos, ou seja, aqueles jogos que trabalham com um tipo de realidade aumentada utilizando de informações de geolocalização do próprio jogador para construir sua própria narrativa, e a música, dentro das noções de espaço sonoro, espaço acústico e paisagem sonora, por meio do jogo GPS Coquetel Musical.

Os autores trabalham de forma clara o percurso evolutivo das tecnologias, assim como suas consequências e desenvolvimentos teóricos. Desta forma, temos em mãos um texto agradável de ler e bastante instrutivo, principalmente no que diz respeito à evolução tecnológica e sua terminologia específica. Por outro lado, o espaço da música presente no título do texto aparece de maneira tímida, deixando margem para que futuras pesquisas explorem mais intensamente a dinâmica entre jogador/sujeito e cenário/cidade tendo em vista que tais interações fazem emergir novas práticas e novos modos de usufruir do ambiente urbano.

O terceiro texto da segunda parte, Paratextos e protocolos de escuta: Atualização do conceito de álbum a partir de aplicativos móveis de Lucas Waltenberg e Diego Brotas, explora como diferentes materialidades, formatos e suportes alteram as dinâmicas da fruição musical ao mesmo tempo em que modificam e ampliam a noção de álbum. Sendo assim, os autores apontam os conceitos de paratexto e protocolos de escuta como elementos analíticos e classificatórios inerentes a todo e qualquer álbum, evocando as materialidades específicas de cada formato e suas respectivas prescrições de práticas.

A análise feita a partir do álbum Biophilia de Björk e do álbum Listen to the light do grupo Bluebrain deixa claro o quanto o conceito de álbum é atualizado conforme suas prescrições de escuta e, consequentemente, sua materialidade. Uma pesquisa interessante, pois amplia nosso repertório conceitual ao invés de procurar cerceá-lo dentro de uma denominação específica, abrindo espaço para outras discussões, como por exemplo, se as playlists que criamos em determinados aplicativos seriam abarcadas nesta noção de álbum. 
No quarto texto desta mesma parte, 'Um artefato que deve ser valorizado': O suporte sonoro fitas cassete como patrimônio cultural da cena do metal de Melina Silva, Natalia Ribeiro e Jeder Janotti Jr., os autores analisam, por meio de entrevistas e entrelaçamentos teóricos, como as práticas, incluindo os modos de uso, agregam valores simbólicos, especificamente, nas dinâmicas envolvendo a materialidade da fita cassete na cena musical do metal.

O ponto alto do texto encontra-se no paradoxo destacado pelos autores de que, independente da materialidade envolvida na dinâmica da fruição musical, esta se revela por um lado, um actante simbólico, imerso em afetos e paixões, mas por outro um fomentador de purismos, aos quais devemos evitar recair. Vale ressaltar que tais análises poderiam ter extrapolado, em dado momento, para outros objetos além da fita cassete, como por exemplo, o disco de vinil, que atualmente tornou-se uma opção de lançamento não só para uma cena underground, mas também para o mainstream, sendo resgatado em diversos lançamentos de diferentes gêneros musicais demonstrando a expansão do tema, pois assim evitariam recorrer a um universo amostral tão específico como foi o caso das duas bandas analisadas. Além disso, questões de pertencimento, identidade e alteridade, ligadas diretamente a noção de valores simbólicos evocados no texto, poderiam contribuir com a discussão da duratividade destas práticas culturais.

O quinto e penúltimo texto, 'Se macumba ganhasse jogo, o campeonato baiano terminava empatado': Notas sobre técnicas sônicas torcedoras, ambiências futebolísticas e mágica de Pedro Marra, trabalha com as interações entre torcida e jogador durante o jogo de futebol. Nesta pesquisa, o autor procura explorar como tal interação é influenciada a partir de um contexto sonoro no qual os participantes estão inseridos e como os cânticos futebolísticos entoados pela torcida acabam por interferir nos afetos da partida por meio do conceito de transdução.

O texto torna-se agradável na medida em que avança quase em tom poético. Contudo, o uso do conceito de transdução e talvez a influência do torcedor no pesquisador, tenham deixado algumas questões um pouco incertas ou pouco comentadas, como por exemplo, o caso no qual a torcida mantém uma relação disfórica com determinado jogador do time ou ainda um jogador que treina para ser mais técnico, pois sabe que suas características emocionais são um fator problemático e, como consequência, não se encontra disponível para a interferência afetiva do outro. Greimas (2002) aponta que a comunicação por meio do sensível, da estesia, só seria possível a partir de uma abertura do sujeito para o mundo, caso o contrário, sua relação seria pautada na racionalidade, na programação, na manipulação. Landowski $(2005 ; 2014)$ explora esta noção dando continuidade na teoria em sua gramática narrativa por meio do que denomina de ajustamento, algo que só ocorreria por meio do contágio e de uma co-presença sensível, o que de fato parece ocorrer em uma partida de futebol na relação torcida e jogadores.

O uso do conceito de transdução possibilitou que o autor mantivesse o foco do texto no som e na sua força, mas também o traiu ao deixar as relações entre os sujeitos 
aparentemente inferiorizadas diante do poder "mágico" do som. Devemos ainda lembrar que a identidade do futebol brasileiro é diferente da identidade do futebol italiano, como o próprio autor bem pontuou, e que isso interfere também nas relações entre os sujeitos, mas além disso, as características espaciais e topológicas do estádio também são responsáveis por prescrever e interferir diretamente nas dinâmicas e nas práticas sociais no estádio, por isso os trabalhos de Demuru $(2014 ; 2017)$ seriam grandes adições neste debate.

O sexto texto da segunda parte e último texto do livro, Som e tecnologias na poesia concreta de Noigandres de Luca Romani, procura, a partir de duas gravações distanciadas entre si por um período de 25 anos do poema Cidade-city-cité de Augusto de Campos, analisar as interações e efeitos fônicos oriundos de tais registros e como estes recursos tecnológicos influenciaram a evolução estética concretista.

Desta forma, o autor nos apresenta uma breve introdução sobre a poesia concreta e as principais características de um movimento que defendia a necessidade de atualizar a estética da poesia, atentando também para suas características plásticas e sonoras. Acompanhar a leitura deste trabalho seguindo as recomendações de escuta do autor, sem dúvida garante uma experiência muito prazerosa e rica no papel didático que este trabalho proporciona.

De fato, ao concluirmos a leitura do texto, pareceu-nos mais clara e fecunda a relação entre as tecnologias sonoras e a proposta da poesia concreta, assim como a contribuição da evolução técnica da primeira possibilitou a ampliação dos efeitos de sentido da segunda. Com muita cautela, o autor finaliza seu texto afirmando que não se trata de uma simples adição de recursos à poesia, mas de uma comunhão de linguagens que potencializam o espaço criativo da poesia permitindo-a revelar sentidos outrora obnubilados.

De maneira geral, após a leitura integral do livro, conseguimos reiterar tudo o que foi dito em sua apresentação: um grupo plural, mas que caminha junto. Este é um livro que, ao refletir a pluralidade do grupo, não se prende a somente uma área do conhecimento, pois suas reflexões estão presentes em diferentes campos. A cada texto lido temos a sensação de que aprendemos algo novo e, ao mesmo tempo, somos convidados ao debate e a refletir sobre as diversas práticas que circunscrevem o sujeito e a sociedade. Sem dúvida é um livro comemorativo, não só para os autores e integrantes do LabCult, mas também para aqueles que possuem a felicidade de ler esta obra.

Alexandre Provin Sbabo é doutorando em Comunicação e Semiótica pela Pontifícia Universidade Católica de São Paulo - PUC-SP e pesquisador do Centro de Pesquisas Sociossemióticas.

alexandre_sbabo@hotmail.com 


\section{Referências}

COSTA, L. Revista Elle Brasil: Da mídia impressa à transmidiação. Dissertação de Mestrado. Pontifícia Universidade Católica de São Paulo. Programa de Pós-Graduação em Comunicação e Semiótica. São Paulo, 2016.

DEMURU, P. Novos Estádios para São Paulo: rumos do futebol e destinos da cidade. In: Ana Claudia de Oliveira (org.). São Paulo e Roma: Práticas de vida e sentido. 1. ed. São Paulo: Estação das Letras e Cores, 2017, v. 1, p. 353-372.

Reescrever os estádios. In: Ana Claudia Mei Aves de Oliveira (org.). Do inteligível ao sensível.

1. ed. São Paulo: Estação das letras e cores, 2014.

GREIMAS, A. J. Da imperfeição (tradução de Ana Claudia de Oliveira). São Paulo: Hacker, 2002

LANDOWSKI, E. A sociedade Refletida: ensaios de sociossemiótica. São Paulo: Educ/Pontes, 1992.

Presenças do outro. São Paulo; Perspectiva, 2002.

. Aquém ou além das estratégias, a presença contagiosa in Documentos de estudo do Centro de Pesquisas Sociossemióticas. São Paulo: Edições CPS, 2005.

Interações arriscadas. São Paulo: Estação das Letras e Cores 2014. 